\title{
Opinions and Practice on Research among Nurses in Sri Lanka
}

\author{
Karthijekan, $\mathbf{K}^{1^{*}}$, Sujendran, $\mathbf{S}^{2}$, Genoosha, $\mathbf{N}^{3}$ \\ ${ }^{1 *},{ }^{2},{ }^{3}$ Department of Supplementary Health Sciences, Faculty of Health-Care Sciences, Eastern University, Sri Lanka \\ DOI: 10.29322/IJSRP.11.05.2021.p11352 \\ http://dx.doi.org/10.29322/IJSRP.11.05.2021.p11352
}

\begin{abstract}
Nursing is a professional practice. Evidence-based practice is important in improving the quality of nursing care. Lack of research knowledge and less involvement in research are the main barriers to evidence-based practice in improving nursing clinical practice. The study aimed to assess the opinions and practice on research among nurses in the selected hospital in Batticaloa district, Sri Lanka. A sample of 270 nurses was selected using a systematic sampling technique. A self-administered questionnaire assessed the socio-demographic characters, nurses' opinions towards research, and practices on research. The opinions questions were answered using "Yes", "No" and "Do not know". A descriptive statistical test was used and results were present as a percentage. Out of 270 participants, the majority $(73.0 \%)$ of them were female, Tamil (76.3\%), diploma holders $(78.9 \%)$, had more than ten years of experience in nursing (45.6\%) and did not participate in any research seminars $(81.5 \%)$. A few numbers of participants $(10.7 \%)$ carried out the research. The majority of the participants mentioned that the research is conducted to improve the nurse's professional development $(90.0 \%)$, difficult to change the practice based on the research findings (71.5\%), and insufficient equipment to transfer research findings into practice (53.0\%). The findings of this study showed that involvement in research was poor among participants even though the majority of them identified research will help to improve their professional careers. Therefore, the educational program that consists of research methodology, and dissemination of research findings could be initiated among this target population to enhance their involvement in research and improve their clinical practice.
\end{abstract}

Index Terms- Research, Practice, Opinion, Nurses, Sri Lanka

\section{INTRODUCTION}

American Nurses'Association Commission is defined as the nursing research "the creation of new knowledge and or the use of existing knowledge in a new and creative way to generate new concepts, methodologies, and understandings"[1]. Nursing is a professional practice. It is undergoing great changes and challenges in the full filling of individual and social needs. So it must be research-based [2]. The main purposes of nursing research are to provide a scientific basis for the nursing profession, develop and evaluate new techniques for delivering patient care that is vital to patient's needs, provide solutions to problems concerning health maintenance, health delivery, and health care, and to prepare oneself to be a diligent practitioner of research [3]. In nursing, clinical practice without research is a practice based on tradition no validation, and it is less desirable in the $21^{\text {st }}$ modern era of Evidence-Based Practice [4]. Evidence-Based Practice is the process by which nurses make clinical decisions using the best available research evidence, their clinical expertise, and considering the patient preferences and values [5]. Applying research evidence to clinical practice may not only promote the quality of nursing care but also can lead to enhance nurses' personal and professional performance [6]. Evidence-based practice is important in improving the quality of nursing care [7].

This publication is licensed under Creative Commons Attribution CC BY.

http://dx.doi.org/10.29322/IJSRP.11.05.2021.p11352

WwW.ijsrp.org 
Lack of research knowledge and less involvement in research are the main barriers to evidence-based practice in improving nursing clinical practice. Some studies were conducted in other countries to assess the nurses' involvement in research, and opinions towards research. But no studies were done in Sri Lanka. Every year nearly 2000 nurses are attaching to health services but a fewer number of nursing staff is conducting researches [8]. Therefore, this research is conducted in the selected hospital in Batticaloa district Sri Lanka to assess the nurses' involvement and their opinions towards research.

\section{METHODOLOGY}

A descriptive cross-sectional study was conducted for one year from January 2019. A sample of 270 nurses was selected from the different hospitals in Batticaloa district, Sri Lanka using a systematic sampling technique. Selected nurses were invited to participate in the study after written informed consent. This study was approved by the Ethics Review Committee, Faculty of Health-Care Sciences, Eastern University, Sri Lanka.

\section{Data collection instrument}

Data were collected by investigators through a self-administered questionnaire. The study instrument initially was developed in English. Then it translated into Tamil and Sinhala. Pre-testing was carried out among 10 nurses to validate the questionnaire for accountability and accuracy. The questionnaire was distributed to the participants in their language as Tamil and Sinhala. Data included socio-demographic characters, research practice, and opinions towards research. The opinions questions were answered using "Yes", "No" and "Do not know".

\section{Statistical analysis}

Collected data were transferred to Statistical Package for Social Sciences (SPSS) version 18 and analyzed based on the research problem, objectives, and variables. A descriptive statistical test was used and results were present as a percentage.

Table 1: Socio-demographic Characteristics of participants

\section{RESULTS AND FINDINGS}

\begin{tabular}{lrr}
\hline Variables (n=270) & Number & Percentage (100\%) \\
\hline Sex & & \\
Male & 73 & 27.0 \\
Female & 197 & 73.0 \\
Age (Years) & & 26.3 \\
20-29 & 11 & 37.0 \\
$30-39$ & 62 & 23.0 \\
$40-49$ & 37 & 13.7 \\
More than 50 & & 76.3 \\
Ethnicity & 206 & 13.0 \\
Tamil & 35 & 10.0 \\
Sinhala & 27 & 0.7 \\
Muslim & 2 & 12.6 \\
Burger & & 78.9 \\
Educational status & 34 & 7.8 \\
Advanced level & 213 & 0.7 \\
Diploma & 21 & 4.8 \\
Undergraduate & 2 & 34.1 \\
Postgraduate & & 15.6 \\
Working experience & 13 & 45.6 \\
$\quad$ Less than one year & 92 & \\
1-5 years & 42 & 123 \\
6-10 years & & \\
More than 10 years &
\end{tabular}

This publication is licensed under Creative Commons Attribution CC BY.

http://dx.doi.org/10.29322/IJSRP.11.05.2021.p11352 


\begin{tabular}{lrr}
\hline Working position & & \\
Staff Nurse Grade-III & 131 & 48.5 \\
Staff Nurse Grade-II & 86 & 31.9 \\
Senior staff & 38 & 14.1 \\
Ward in charge & 10 & 3.7 \\
Matron & 5 & 1.9 \\
Participation in research seminars & 50 & 18.5 \\
Yes & 220 & 81.5 \\
No
\end{tabular}

The study was conducted among 270 nurses in selected hospitals in Batticaloa district, Sri Lanka. Among the 270 participants, the majority (73.0\%) of the participants were female, Tamil (76.3\%) diploma holders (78.9\%), had more than ten years of experience in nursing (45.6\%), and did not participate in any research seminars $(81.5 \%)$. Socio-demographic details are given in table 1.

\section{Research involvement}

Out of 270 participants, A few numbers of participants (10.7\%) carried out the research. Of these, the majority of them (93.1\%) carried out less than three research and one-third of them (34.1\%) disseminated their findings mainly at the national conferences.

\section{Opinions toward research}

The participants were asked using seven questions regarding their opinions towards research and their responses were recorded as "yes" or "no" or "don't know". The majority of the participants mentioned that the research is conducted to improve the nurse's professional development (90.0\%), difficult to change the practice based on the research findings (71.5\%), and insufficient equipment to transfer research findings into practice (53.0\%). The opinions towards research are given in table 2.

Table 2: Participants' opinions towards research

\begin{tabular}{|c|c|c|c|}
\hline Variables $(n=270)$ & Yes $(\%)$ & No $(\%)$ & Don't know (\%) \\
\hline I think research is done to improve professional practices & 90.0 & 6.3 & 3.7 \\
\hline $\begin{array}{l}\text { There is not enough administrative support to be able to } \\
\text { transfer research findings into practice }\end{array}$ & 21.5 & 44.8 & 33.7 \\
\hline $\begin{array}{l}\text { It is impossible to make any changes in patient care } \\
\text { practices according to research findings }\end{array}$ & 16.3 & 71.5 & 12.2 \\
\hline $\begin{array}{l}\text { Because it is hard to change nurses' habits, we cannot } \\
\text { reflect research findings in our practices }\end{array}$ & 16.3 & 72.6 & 11.1 \\
\hline $\begin{array}{l}\text { There is not sufficient equipment to transfer research } \\
\text { findings into practice }\end{array}$ & 53.0 & 21.9 & 25.2 \\
\hline $\begin{array}{l}\text { I do not think research findings are beneficial for the } \\
\text { profession }\end{array}$ & 5.6 & 87.4 & 7.0 \\
\hline $\begin{array}{l}\text { Research benefits only the researcher and contributes to } \\
\text { her/his development }\end{array}$ & 17.0 & 70.7 & 12.2 \\
\hline
\end{tabular}

\section{DISCUSSION}

This publication is licensed under Creative Commons Attribution CC BY. 
The nursing profession is a dynamic clinical service that is supported by a unique body of knowledge that is developed by the research process. It's very much important to make changes in the environment and the client's health care needs. In the mid-1970s most of the nurses work beside in hospitals but presently more nurses are finding themselves involved in nursing researches [4]. Many studies have been done worldwide to assess the nurses' involvement, attitudes, and barriers to do research. However, no studies were conducted in Sri Lanka, Therefore, this study was conducted to assess the nurses' involvement in research, and opinions towards research in the selected hospital in the Batticaloa district in Sri Lanka.

The present study found that the majority of the nurses are not involved in research activity although they knew that research could be helped to improve their professional development. This study found that the majority of the participants perceived research is conducted to improve the nurse's professional development however it is difficult to change the practice based on the research findings, and insufficient equipment to transfer research findings into practice (53.0\%). A descriptive study was carried out with similar aspects found that all the nurses had a positive attitude towards evidencebased practice and two-third of clinical nurses (85.5\%) and nurses' educators (73.8\%) were reported that they had insufficient time at the workplace to search and read articles [5]. In a descriptive cross-sectional research study of nursing practice, knowledge, attitudes, and perceived barriers to evidence-based practice at an academic medical center. The data was collected from 458 nurses who work in an academic medical center in California. The results were nearly nineteen percent of the participants reported that they had great barriers (lack of time, nursing autonomy, and learning opportunities) in doing research. The strongest correlation was found between barriers and practice, knowledge, and attitude related to evidence-based practice [9].

\section{CONCLUSION AND RECOMMENDATIONS}

This study reveals that most of the participants are unaware of how to engage in research due to inadequate knowledge of research methodology. The involvement in research was poor among participants even though the majority of them identified research will help to improve their professional career. Hospital authority and the health system to include an educational program that consists of research methodology, and dissemination of research findings to the participants which could be helped to enhance their involvement in research.

\section{ACKNOWLEDGEMENT}

The authors would like to acknowledge the director, medical supernatants, and matrons of selected hospitals where the sample was recruited, in Batticaloa district, Sri Lanka, and the nurses for their valuable support in conducting the study.

\section{REFERENCES}

[1] American Nurses Association Commission on Nursing Research. "Generating a scientific basis for nursing practice: Research priorities," Nursing Research., vol 29, pp.219, 2010.

[2] M. Allen and J. Levy, "Evidence-based searching for nursing and allied health," Bibliotheca Medica Canadian., vol 23, pp.90-95, 2002.

[3] "Characteristics and purpose of nursing research," Available: http://nursingfile.com/nursing research/characteristics-and purpose of nursing research.html. [Accessed March 15, 2017].

[4] S. Adejumo, P. O. Guobadia, and P.Ojekou, "Nurses' attitude to reading research articles and their perception of research utilization in clinical practice in a Nigerian city," JMBR., vol 12, pp.46-56, 2013. 
[5] M. M. Mohsen, N. A.Safran, and O. M.Okby, "Nurses' Perception and Barriers for Adaptation of Evidence-Based Practice in Primary Care: Bridging the Gap," AJNR., vol 4, pp.25-33, 2016.

[6] W.T. Chien, Q. Bai, W. K. Wong, H. Wang, and X. Lu, "Nurses' perceived barriers to and facilitators of research utilization in mainland china: a cross-sectional survey," Open Nurs J., vol 5, pp.314-322, 2013.

[7] E. Shafiei, A. Baratimarnani, S. Goharinezhad, R. Kalhor, and M. Azmal, "Nurses' perception of evidence-based practice: a quantitative study at a teaching hospital in Iran," Med J Islam Repub IRAN., vol 28, pp.135, 2014.

[8] "Ministry of Health Annual Health Bulletin Sri Lanka 2013," Available: http://www.health.gov.lk/en/publication [Accessed March 10, 2017].

[9] "Nursing practice, knowledge, attitudes, and perceived barriers to evidence-based practice at an academic medical center," Available: http://escholorship.org/uc/item/47m7p92r [Accessed March 10, 2017].

\section{Authors}

First Author - Karthikesu Karthijekan, Lecturer, Department of Supplementary Health Sciences, Faculty of Health-Care Sciences, Eastern University, Sri Lanka

Second Author - Sangarapillai Sujendran, Senior Lecturer, Department of Supplementary Health Sciences, Faculty of Health-Care Sciences, Eastern University, Sri Lanka

Third Author - Genoosha Namassevayam, Lecturer, Department of Supplementary Health Sciences, Faculty of HealthCare Sciences, Eastern University, Sri Lanka

Correspondence Author - Karthikesu Karthijekan, jeshikarthi@gmail.com, Mobile: +94772029816 